\title{
MICROSTRUCTURALAND MECHANICAL PROPERTIES OF SELECTIVE LASER MELTED INCONEL 718 FOR DIFFERENT SPECIMEN SIZES
}

\author{
Bartosz Madejski ${ }^{1}$ O ORCID 0000-0002-8000-6108 \\ Maciej Malicki ${ }^{1}$ • ORCID 0000-0002-2570-2290 \\ Sławomir Czarnewicz ${ }^{1}$ • ORCID 0000-0002-7530-6659 \\ Konrad Gruber ${ }^{2}$ O ORCID 0000-0003-1357-2473
}

${ }^{1}$ Łukasiewcz Research Network - Institute of Aviation, Al. Krakowska 110/114, 02-256 Warsaw, Poland

${ }^{2}$ Wrocław University of Science and Technology, Faculty of Mechanical Engineering, Łukasiewicza Street 5, 50-371 Wrocław, Poland

Bartosz.Madejski@ilot.lukasiewicz.gov.pl, Maciej.Malicki@ilot.lukasiewicz.gov.pl, Slawomir.Czarnewicz@ilot.lukasiewicz.gov.pl,konrad.gruber@pwr.edu.pl

\begin{abstract}
Selective laser melting (SLM) falls into the category of additive manufacturing technologies that are being increasingly used in the aerospace industry. This study presents the results of the examination of the microstructure and mechanical properties of selective laser melted Inconel 718. The tests were carried out for samples of different geometry (thickness, shape). The investigation showed the effect of the specimen's size and the printing direction on the microstructure and mechanical properties. In the microstructural investigation, light and scanning electron microscopes were used. The microstructure investigation included measurements of the grain size and the carbides' content. In order to estimate porosity computer tomography was used. Tensile tests were carried out at room temperature. The results showed differences in mechanical and microstructural properties of different size specimens.
\end{abstract}

Keywords:: additive manufacturing, tensile test, microstructure investigation, IN718, Inconel 718.

Article Category: Research Article

\section{INTRODUCTION}

Selective laser melting (SLM) enables manufacturing monolithic volumes and complex geometries. In SLM parts are created in a layer-by-layer manner, directly from 3D CAD models. For SLM parts, heat treatment and surface finish are usually applied 
to achieve better results. Understanding the effect of heat treatment and surface condition on the microstructure and mechanical properties of SLM parts helps to achieve a better design of the final part $[1,2,3]$.

The objective of the study was to show how the size and the manufacturing direction of the samples affect the mechanical and microstructural properties of IN718 alloy. Inconel 718 has excellent thermal resistance of up to $700^{\circ} \mathrm{C}$ and it is widely used in the aviation industry for turbine disks, blades or shafts. This alloy has also high mechanical properties, very good resistance to bending and fatigue endurance limit. Additionally, IN718 is suited for the SLM technique $[1,2,3]$.

The work was undertaken to meet the aerospace industry needs. It has been performed under the strategic programme of the National Centre for Research and Development "Modern Materials Technologies - TECHMATSTRATEG".

\section{MATERIALS AND METHODS / PROCEDURE}

Mechanical tests were performed for heat treated INCONEL 718 alloy, manufactured in three printing directions $\left(0^{\circ}, 45^{\circ}, 90^{\circ}\right)$ and for two specimen types (Table 1). For each test conditions, 3 samples were tested. All samples before machining and tensile tests were heat treated according to Table 2.

Table 1. Test plan for tensile tests.

\begin{tabular}{|c|c|c|c|c|c|c|}
\hline Alloy & $\begin{array}{c}\text { Heat } \\
\text { treatment }\end{array}$ & $\begin{array}{c}\text { Printing } \\
\text { direction }\end{array}$ & $\begin{array}{c}\text { Test } \\
\text { temp. }\end{array}$ & Drawing type & $\begin{array}{c}\text { No. of the sample per } \\
\text { one test condition }\end{array}$ & SUM \\
\hline 1 & 1 & 3 & 1 & 2 & 3 & $\mathbf{1 8}$ \\
\hline Inconel 718 & HT & $\begin{array}{c}00 \text { degree } \\
45 \text { degree } \\
90 \text { degree }\end{array}$ & $22 \mathrm{C}$ & $\begin{array}{c}\mathrm{D} 5-\mathrm{d}=4,06 \mathrm{~mm} \\
\mathrm{D} 6-\mathrm{d}=6,35 \mathrm{~mm}\end{array}$ & - & \\
\hline
\end{tabular}

Static tensile tests were performed for two types of specimens (D5 and D6) in order to show how differences in a sample's size affect its mechanical properties. The geometry (Fig. 1) of the test specimens and tensile testing procedures were carried out in accordance with the ASTM E8/E8M-16a standard.

Table 2. Heat treatment parameters.

\begin{tabular}{|c|c|c|c|c|}
\hline Type & Stress relieving & HIP & Solutioning & Ageing \\
\hline HT & $\begin{array}{c}1150^{\circ} \mathrm{C} / 6 \mathrm{~h} / \text { parts } \\
\text { on platform } / \mathrm{FC}\end{array}$ & N/A & $1100^{\circ} \mathrm{C} / 1 \mathrm{~h} / \mathrm{WC}$ or $\mathrm{AC}$ & $\begin{array}{c}718^{\circ} \mathrm{C} / 8 \mathrm{~h}+621^{\circ} \mathrm{C} / \text { to } \\
18 \mathrm{~h} / \mathrm{AC}\end{array}$ \\
\hline HT0 & $\begin{array}{c}1150^{\circ} \mathrm{C} / 6 \mathrm{~h} / \text { parts } \\
\text { on platform } / \mathrm{FC}\end{array}$ & N/A & N/A & N/A \\
\hline
\end{tabular}

Tensile tests were carried out at room temperature at a strain rate of $0.005[\mathrm{~mm} / \mathrm{mm} / \mathrm{min}]$ up to yield strength $(0.2 \%)$ and after that rate increased to $0.05[\mathrm{~mm} / \mathrm{mm} / \mathrm{min}]$ and the test was performed up to rupture. The goal of performing tensile tests was to determine Yield Strength $0.2 \%$ (YS 0.2\%), ultimate tensile strength (UTS), Young's modulus (E), elongation, and reduction of area [6]. 
D5

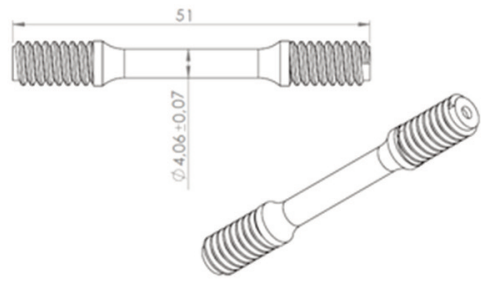

D6

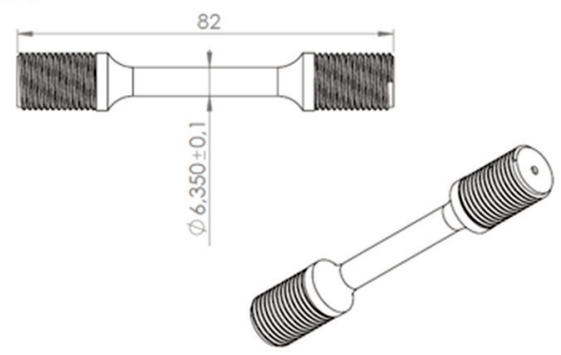

Fig. 1. Drawings of the samples D5 and D6 for tensile tests.

For the microstructure investigation, the raw bars 3 and $6 \mathrm{~mm}$ in diameter and the plate type specimen (Fig. 2) were built. From the raw bars and the plate type specimen, the metallographic cross sections in the planes perpendicular and parallel to the longitudinal axis of the raw bars/plate type specimens were prepared.
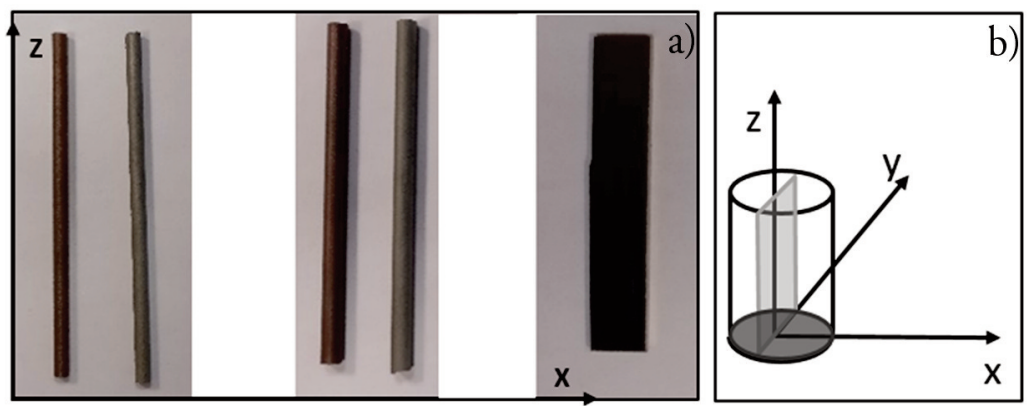

Fig. 2. Raw bars $\mathrm{d}=3 \mathrm{~mm}, \mathrm{~d}=6 \mathrm{~mm}$ and plate type sample (1x10x100 $\mathrm{mm})$ for microstructure investigation (a) and metallographic orientation with respect to the specimen axis (b).

The metallographic cross sections were etched using etchant no. 22 according to ASTM E 407 for the grain size evaluation and Kalling's etchant 1 for the carbides content evaluation. The grain size evaluation was carried out using the ASTM E 112 Heyn intercept method. The microstructure investigation was performed for Inconel 718 after HT and HT0 heat treatment (Table 3) with Keyence VHX6000 microscope. For the same raw bars and plate type specimen the CT scans were generated (Fig. 3) with a GE v/tome/xs 240 tomograph.

Table 3. Test plan for microstructure investigation.

\begin{tabular}{|c|c|c|c|c|}
\hline Alloy & Heat treatment & Printing direction & Drawing type & SUM \\
\hline 1 & 2 & 3 & 3 & $\mathbf{1 8}$ \\
\hline \multirow{3}{*}{ Inconel 718 } & HT0 & 00 degree & raw bar $(\mathrm{d}=3 \mathrm{~mm})$ & \\
& HT & 95 degree & raw bar $(\mathrm{d}=6 \mathrm{~mm})$ & \\
& & 90 degree & plate type sample $(1 \times 10 \times 100 \mathrm{~mm})$ & \\
\hline
\end{tabular}




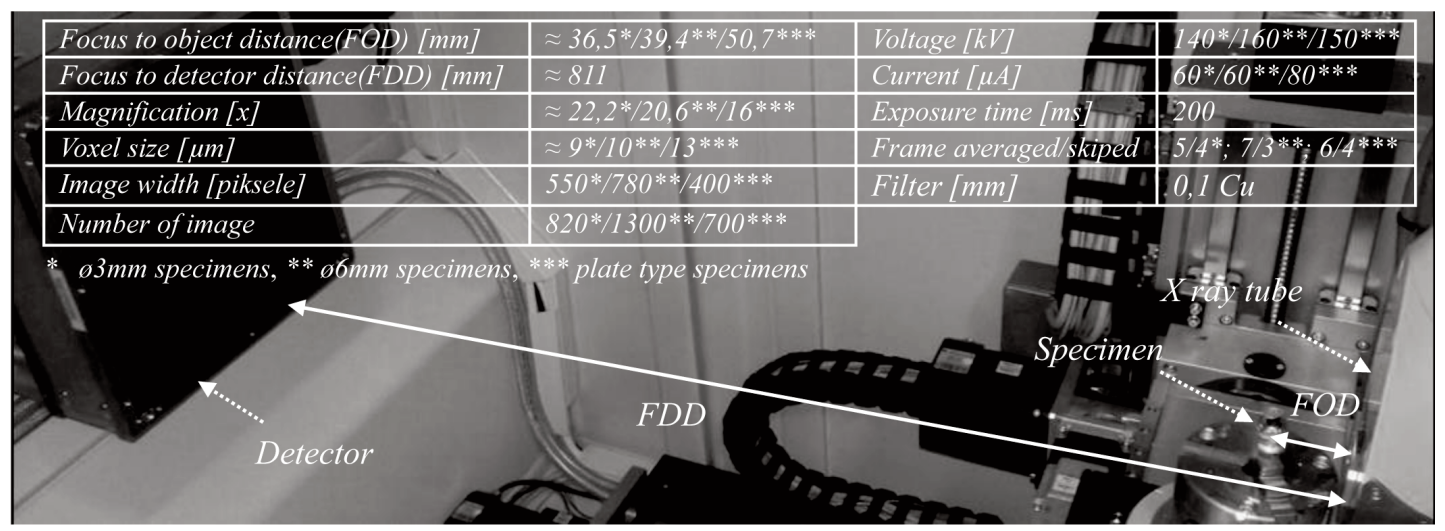

Fig. 3. CT System with parameters used for tested specimens.

\section{RESULTS AND DISCUSSION}

\section{Mechanical tests - results}

Different types of samples were built in order to determine the effect the surface roughness and the printing direction had on the mechanical properties (Fig. 4). The gage section of samples was not machined. The surface of the samples was therefore in the as-built state. This means that after printing, the samples were heat treated, the supports were hand-tool removed and the surface was only sandblasted in order to clean it after the supports had been removed.
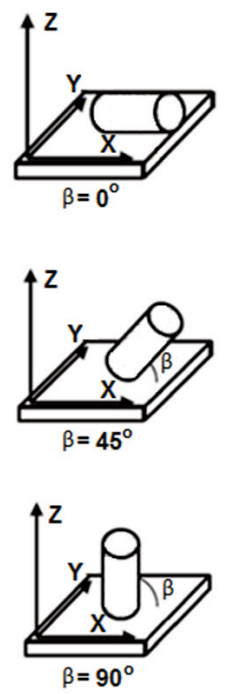

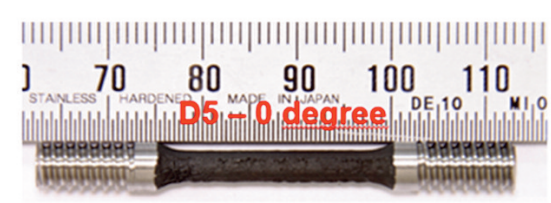

| |||||||||||||||||||||||||||||||||||||||||||||||||||
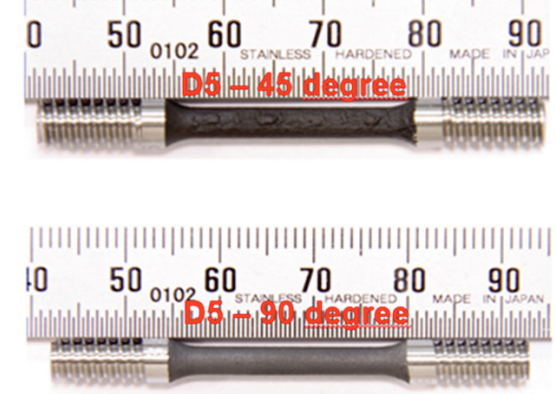
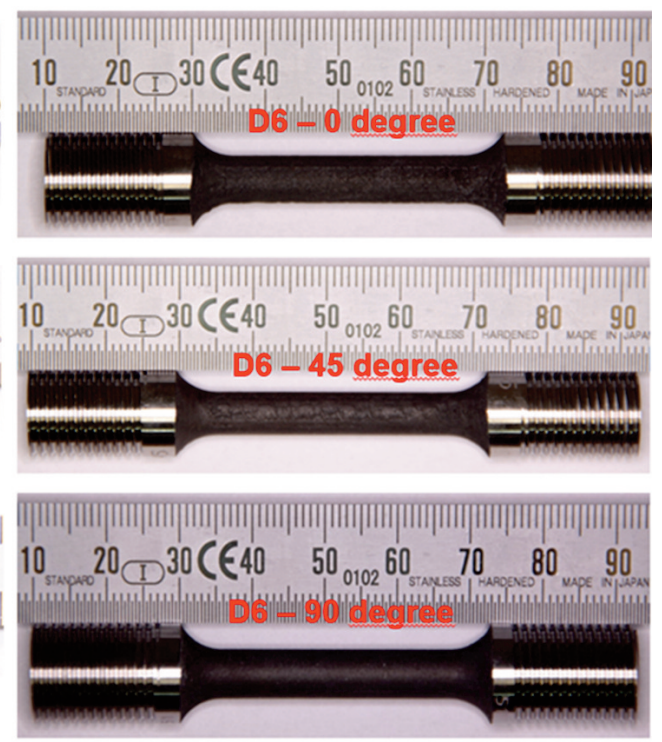

Fig. 4. Tensile tests, samples D5 and D6 (printing direction $0^{\circ}, 45^{\circ}$ and $90^{\circ}$ ).

The requirements for the mechanical properties for IN718 (additively manufactured) are included in the ASTM F3055-14 standard. For each tested specimen size (D5 and D6), the minimum requirements for elongation, ultimate tensile strength (UTS) and the yield strength (YS 0.2\%) as specified in ASTM F3055-14 were obtained (Fig. 5) [4, 5]. 
For some printing directions, it is necessary to use supports in order to manufacture samples without deformations. The samples manufactured in the direction of $90^{\circ}$ (axis Z) do not have supports in the gage section, while the samples printed in the direction of $0^{\circ}$ and $45^{\circ}$ are characterized by a big number of supports with the biggest number of supports required for the printing direction $0^{\circ}$. The number of supports affects the results of mechanical tests. The results for yield strength and ultimate tensile strength are more repeatable for samples without support $\left(90^{\circ}\right)$ compared to samples with supports $\left(0^{\circ}, 45^{\circ}\right)$.

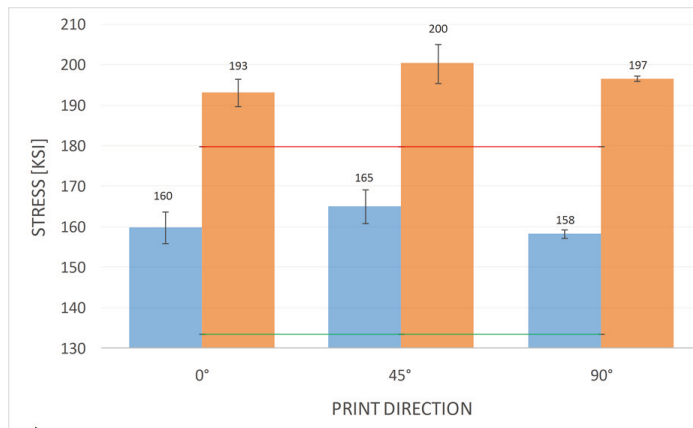

a)

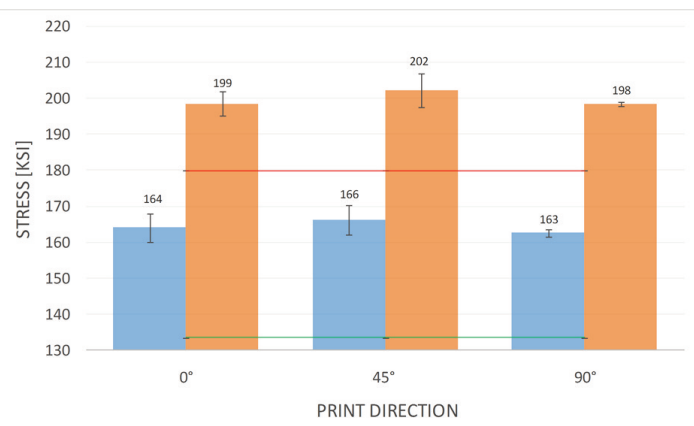

b) $=$ YS $0,2 \%=U$ UTS - ASTM Min. UTS (RT) —ASTM Min. YS (RT)

Fig. 5. Results for tensile tests for samples D5-a and D6-b (yield strength $0.2 \%$ - YS $0.2 \%$, ultimate tensile strength - UTS).

As regards elongation and reduction of area (Fig. 6), it was observed that the printing direction impacted the results more significantly. The lowest elongation and reduction of area was observed for printing direction $0^{\circ}$ while the highest result was obtained for $90^{\circ}$. The supports caused the occurrence of more cracks and pores at the support surface area, which reduced the ductility of the material.

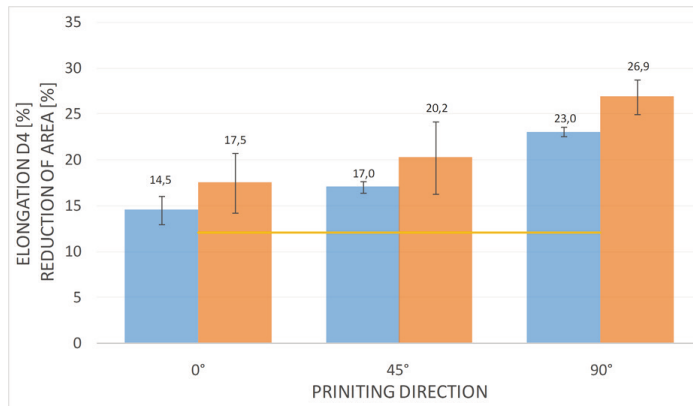

a)

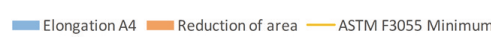

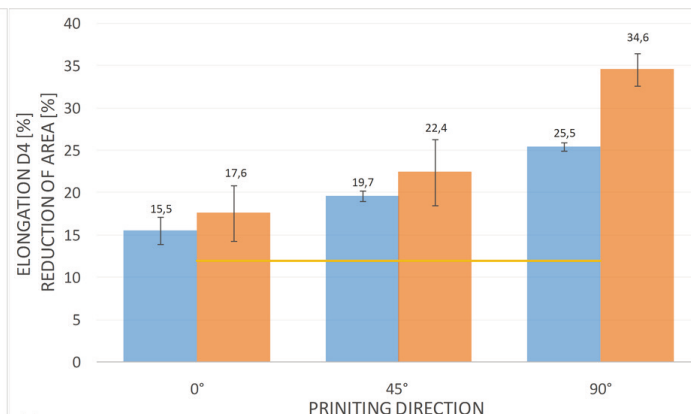

b)

Fig. 6. Results for tensile tests for samples D5-a and D6-b (elongation A4, reduction of area).

The static tensile tests carried out for D6 samples allowed researchers to determine the effect of the size of printed bars on the mechanical properties. The gage section for D6 samples $(\mathrm{d}=6.35 \mathrm{~mm})$ was also of an as-built type, however the diameter of this sample was higher than D5 sample $(\mathrm{d}=4.06 \mathrm{~mm})$. Comparing the results for samples D5 and D6 revealed that the mechanical properties (yield strength $0.2 \%$ and ultimate 
tensile strength) were about $1-4 \%$ higher for D6 samples. This was probably due to a higher percentage of active cross-section than for D5 samples. Defects such as a spherical shape of the gage section, higher roughness, and misalignment of the gage section with respect to the gripping part could affect the repeatability of the results.

\section{Microstructural investigation - results}

Typically, the primary structure of Inconel 718 after SLM, consists of epitaxial groaned columnar grains with a cellular substructure. Also, adverse segregations, Laves phases or MC carbides can be present $[7,8,9,10]$. After HT and HT0 heat treatment epitaxial groaned grain structures were not observed (Fig. 7, 8, 9).

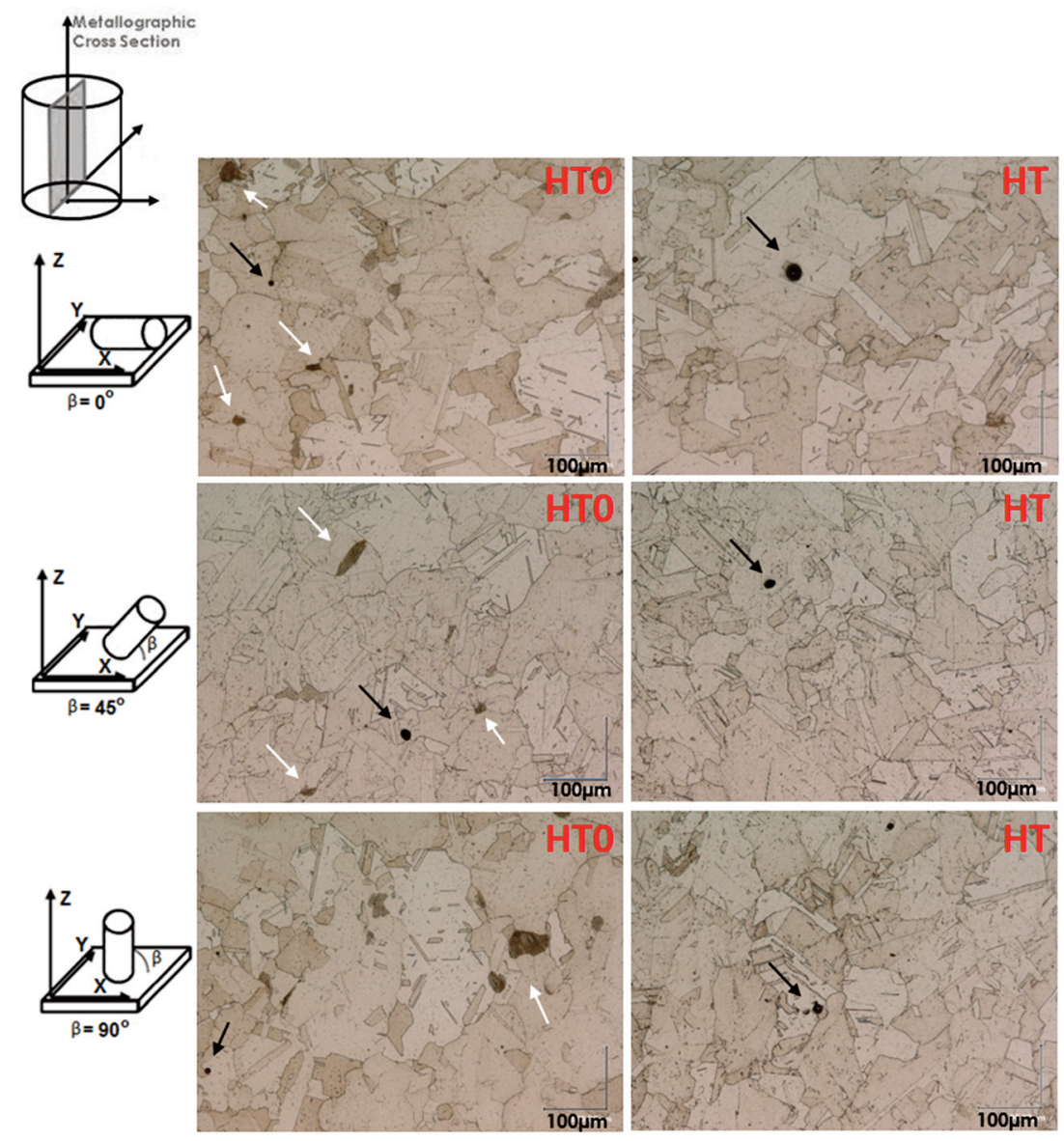

Fig. 7. Structure of Inconel 718 after HT0 and HT heat tratement in $3 \mathrm{~mm}$ raw bars.

In general, there are no significant differences in the observed microstructure between HT and HT0 as well as between different printing directions. The structure after HT and HT0 consists of equiaxed grains with carbides (Fig. 10) in the form of small precipitates distributed in the grains as well as in grain boundaries. There are twin boundaries visible. 


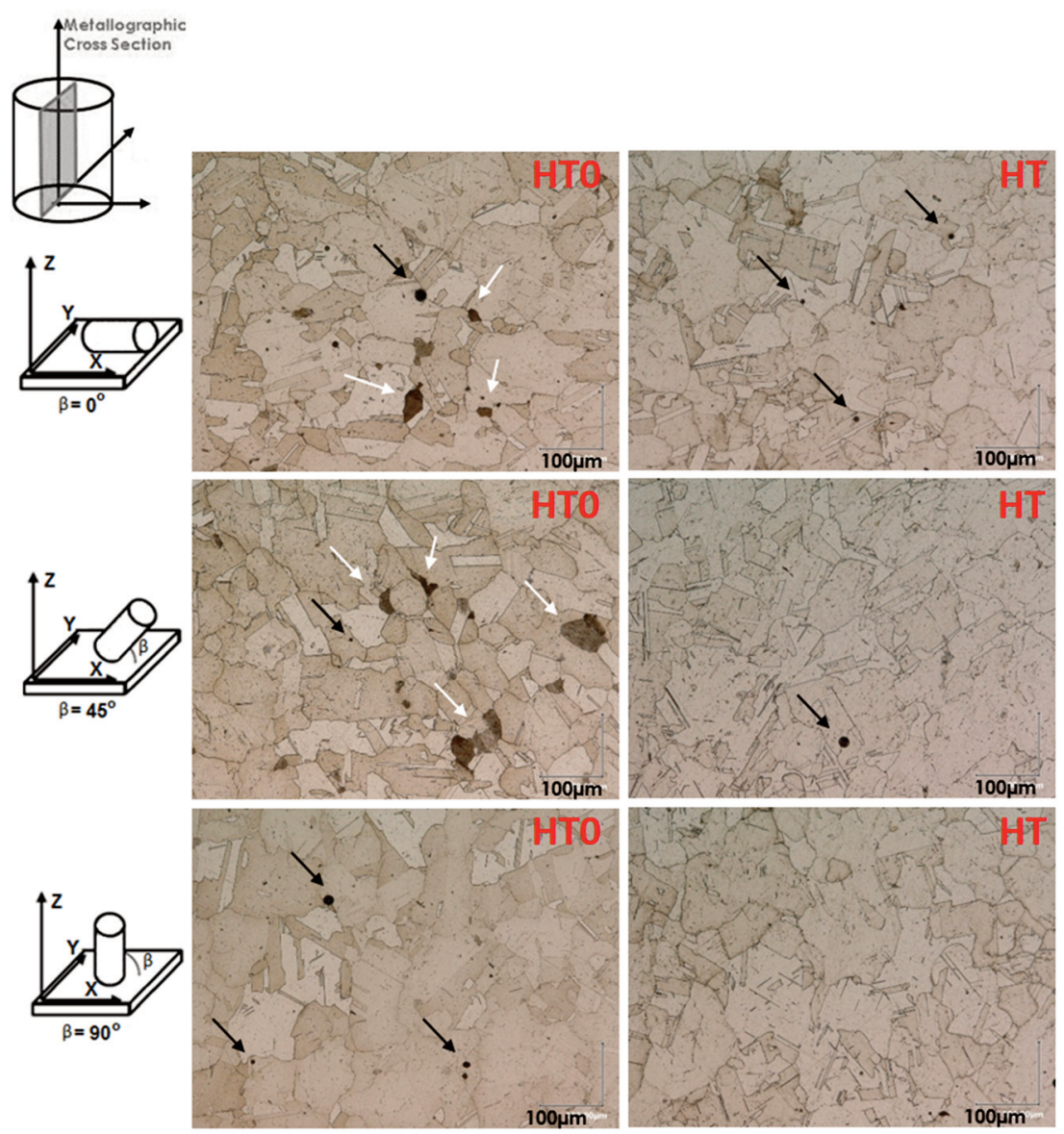

Fig. 8. Structure of Inconel 718 after HT0 and HT heat tratement in $6 \mathrm{~mm}$ raw bars.
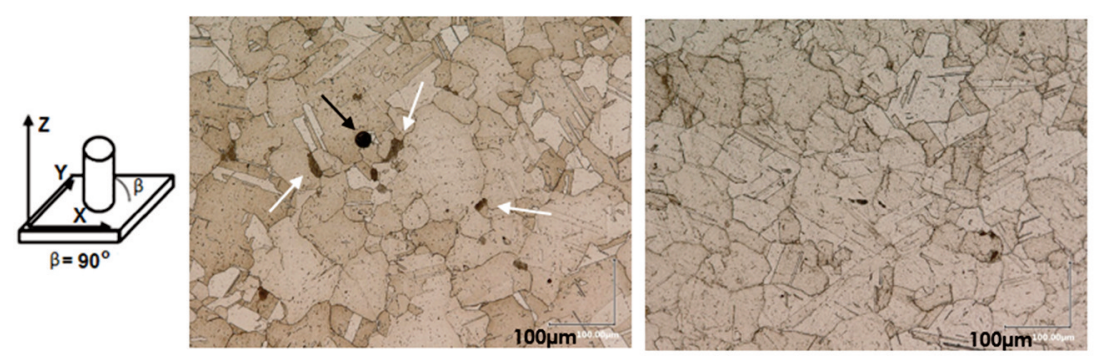

Fig. 9. Structure of Inconel 718 after HT0 and HT heat tratement in plate type specimens.

Some of the grains after HT0 were much darker than the rest of the grains. Such dark grains (white arrows in Fig 7, Fig. 8, Fig. 9) were observed in the stress relieved structure and the dark color is related to the element segregation or cellular substructure from epitaxial grown grains. This may indicate that the recrystallization and homogenization of the material had not been achieved in full [9]. After HT, those darker grains disappeared. Also, in the specimens after HT0 and HT some individual voids (pores) were found (black arrows on Fig. 7, Fig. 8, Fig. 9). 

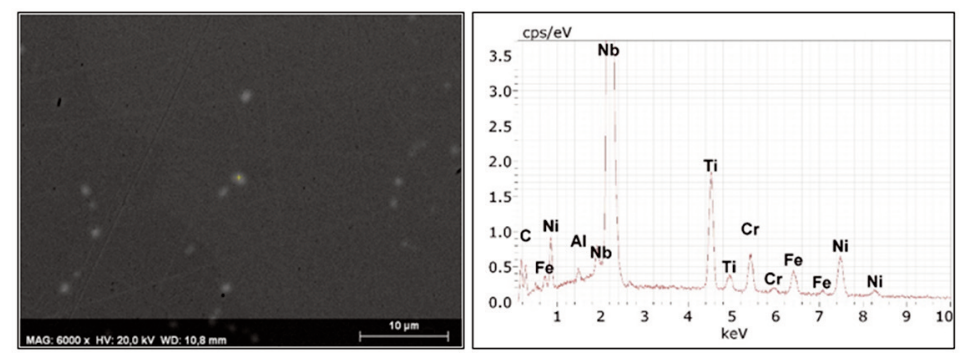

Fig. 10. EDX spectra for precipitations representing carbides in printed Inconel 718 in a bar rod $6 \mathrm{~mm}$ printed in $45^{\circ}$ direction after HT.

The grain size evaluation (Fig. 11, Table 4) showed that after HT the grain size was slightly smaller, but the differences were within the general measurement error.

Table. 4. Numeric values of the grain size measurements for raw bars and plate type specimens.

\begin{tabular}{|c|c|c|c|c|c|c|}
\hline \multirow{4}{*}{$\begin{array}{l}\text { Printing } \\
\text { direction }\end{array}$} & \multicolumn{6}{|c|}{ Grain Size $[\mathrm{G} \pm 95 \% \mathrm{CI}]$} \\
\hline & \multicolumn{6}{|c|}{ Specimen } \\
\hline & \multicolumn{2}{|c|}{$\varnothing 3 \mathrm{~mm}$} & \multicolumn{2}{|c|}{$ø 6 \mathrm{~mm}$} & \multicolumn{2}{|c|}{ plate } \\
\hline & HT0 & $\mathrm{HT}$ & HT0 & $\mathrm{HT}$ & HT0 & $\mathrm{HT}$ \\
\hline $0^{\circ}$ & $4.4 \pm 0.4$ & $4.2 \pm 0.3$ & $4.1 \pm 0.6$ & $4.0 \pm 0.3$ & - & - \\
\hline $45^{\circ}$ & $4.3 \pm 0.4$ & $4.1 \pm 0.3$ & $4.5 \pm 0.3$ & $3.7 \pm 0.3$ & - & - \\
\hline $90^{\circ}$ & $4.6 \pm 0.3$ & $4.3 \pm 0.3$ & $4.6 \pm 0.3$ & $4.5 \pm 0.3$ & $4.6 \pm 0.4$ & $4.6 \pm 0.3$ \\
\hline
\end{tabular}
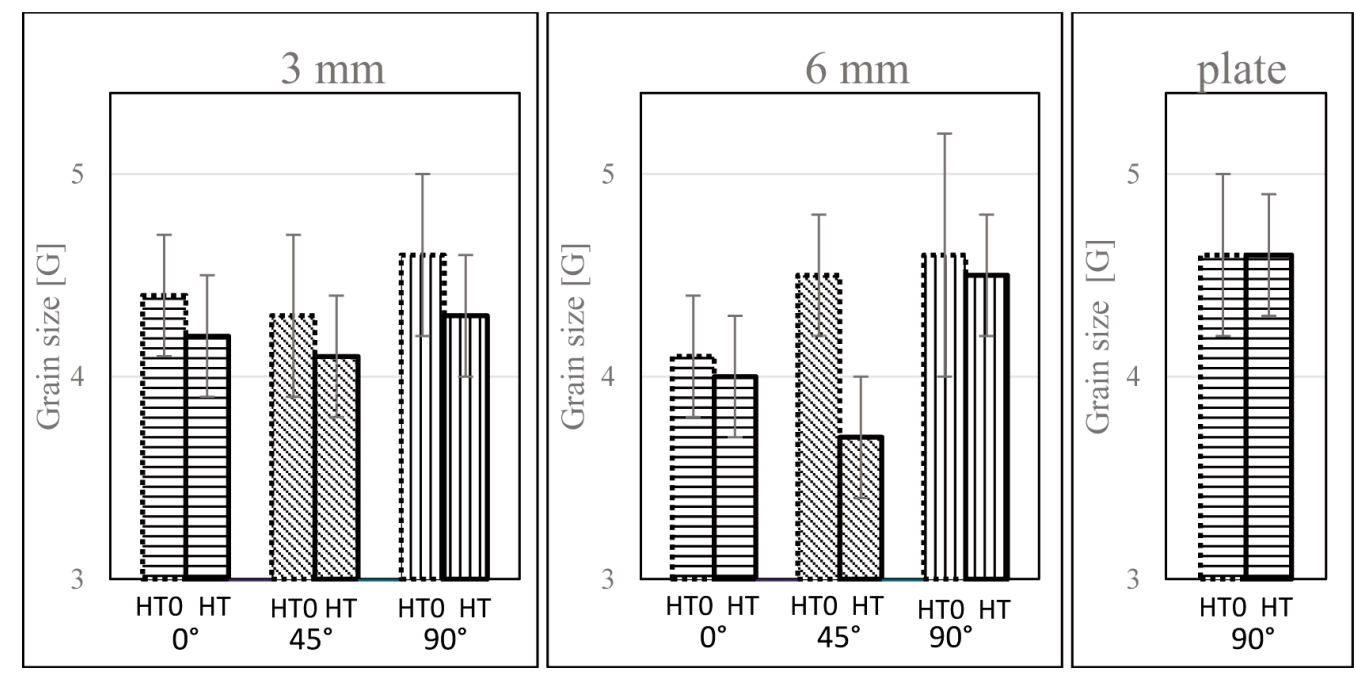

Fig. 11. Grain size evaluation for raw bars and plate type specimens.

It was found that in the surface area of all specimens there were places where the carbides content was much higher than in the volume area (Fig. 12). In general, there were no significant differences between carbide content in the specimens inspected (Fig. 13, Fig. 14). In the metallographic cross section from the raw bars printed in direction $0^{\circ}$ and $45^{\circ}$, in the surface area there was a higher content of voids and presence of lack of fusion and micro cracks, which was most probably associated with the supports (Fig. 15). 

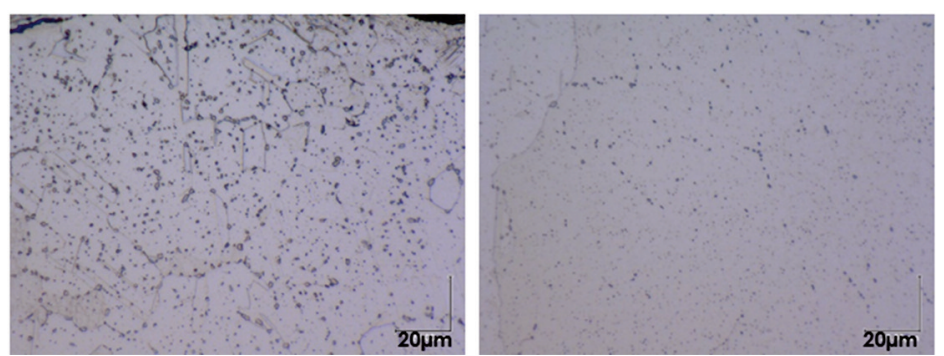

Fig. 12. Carbides in the surface area and in the material volume in one of the printed bar rod.

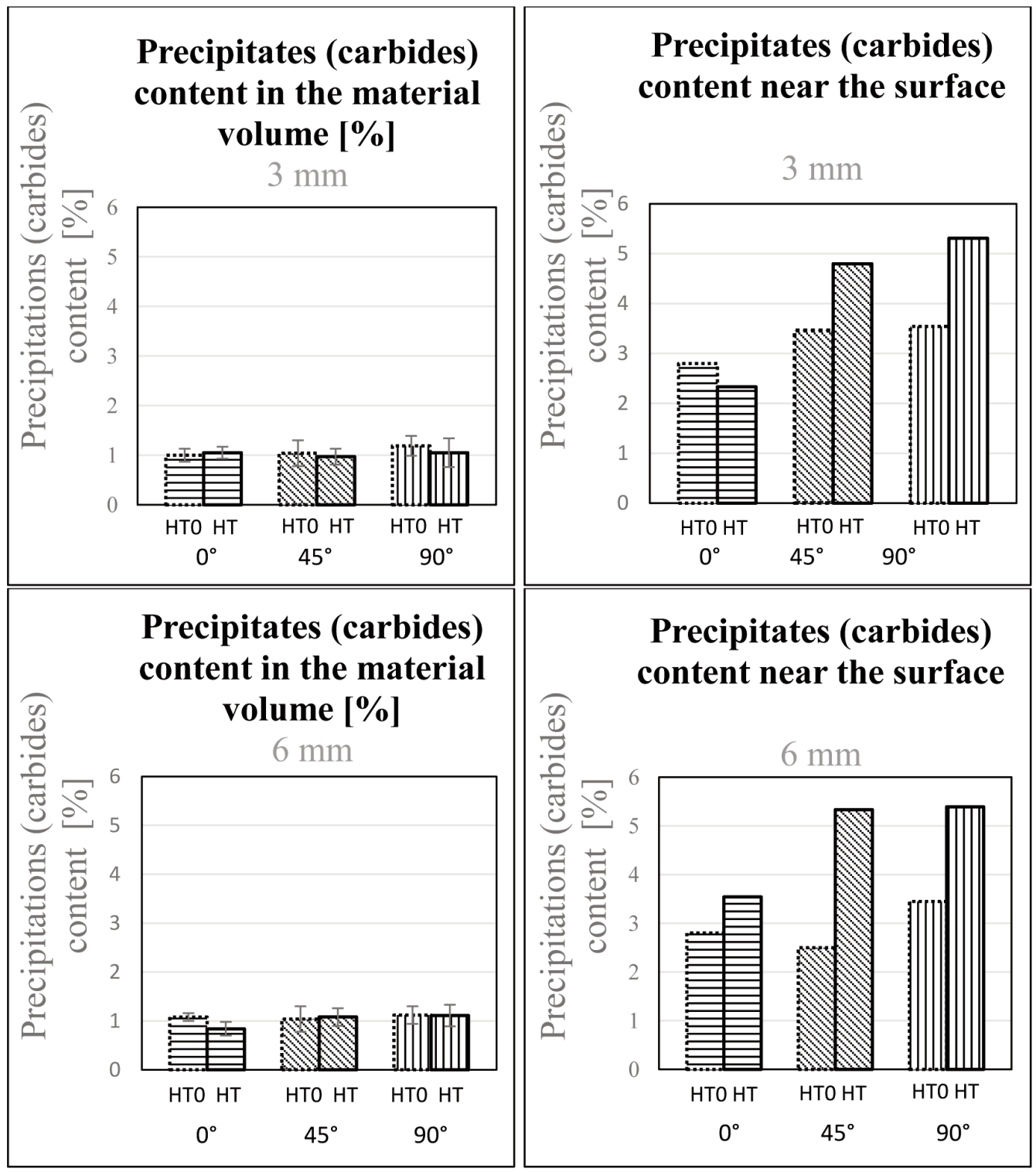

Fig. 13. Carbides content in printed bar rods. 


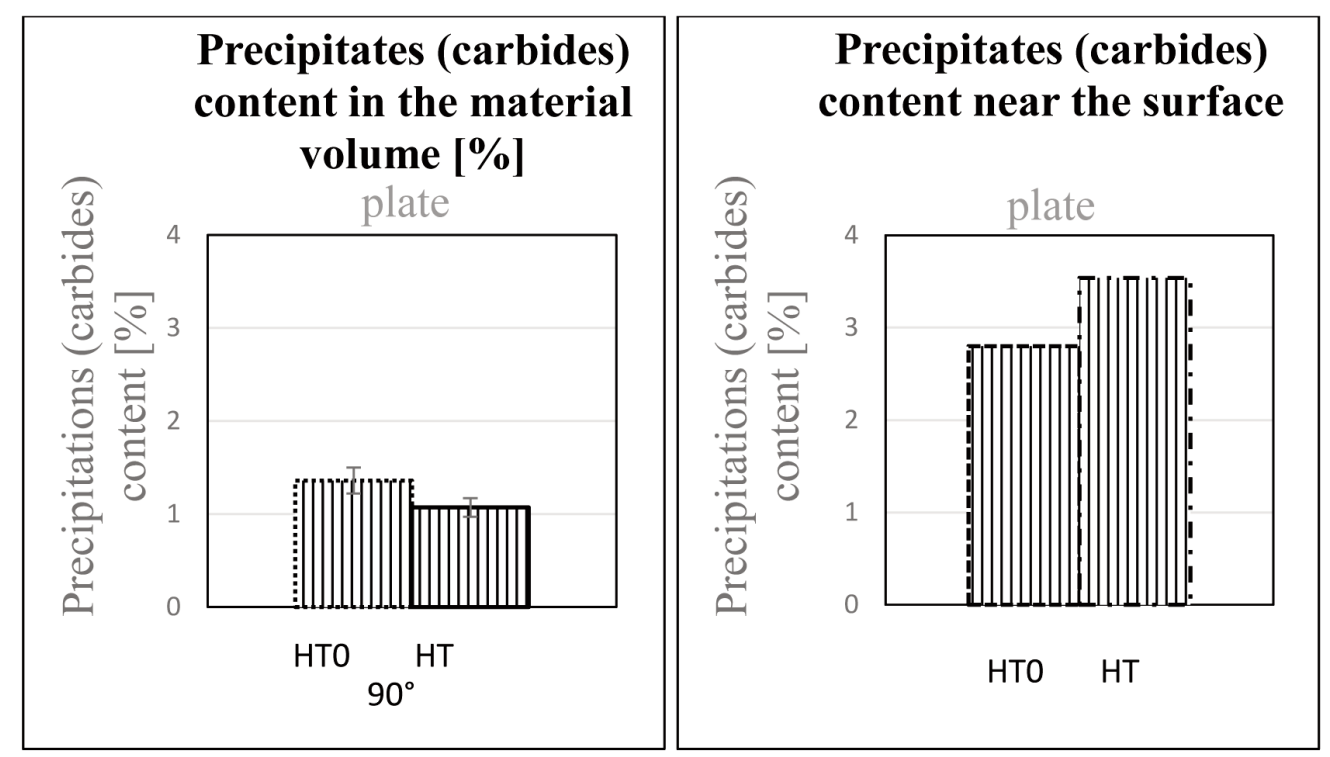

Fig. 14. Carbides content in plate type specimen.
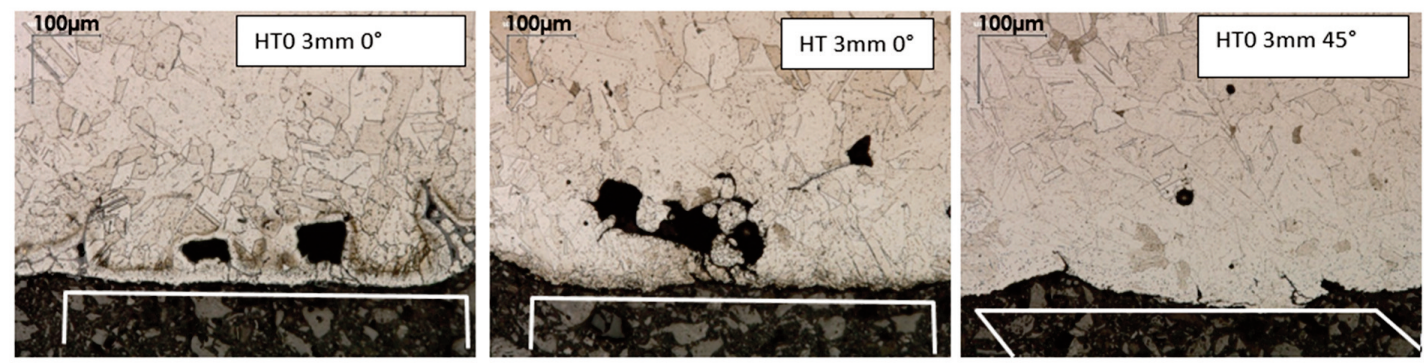

Fig. 15. Support surface area of raw bars printed in $45^{\circ}$ and $0^{\circ}$ direction.

Table 5. CT Estimation of the void volume fraction of the inspected bar rod and plate type specimens.

\begin{tabular}{|l|c|c|c|c|c|c|}
\hline \multirow{3}{*}{$\begin{array}{l}\text { Printing } \\
\text { orientation }\end{array}$} & \multicolumn{6}{|c|}{ Porosity [\%] } \\
\cline { 2 - 7 } & \multicolumn{2}{|c|}{$\varnothing 3 \mathrm{~mm}$} & \multicolumn{2}{c|}{$\varnothing 6 \mathrm{~mm}$} & \multicolumn{2}{c|}{ plate } \\
\cline { 2 - 7 } & $\mathrm{H} 0$ & $\mathrm{H} 2$ & $\mathrm{H} 0$ & $\mathrm{H} 2$ & $\mathrm{H} 0$ & $\mathrm{H} 2$ \\
\hline $0^{\circ}$ & 0.011 & 0.014 & 0.009 & 0.007 & - & - \\
\hline $45^{\circ}$ & 0.005 & 0.003 & 0.011 & 0.002 & - & - \\
\hline $90^{\circ}$ & 0.017 & 0.005 & 0.006 & 0.001 & 0.065 & 0.001 \\
\hline
\end{tabular}

The CT inspection revealed voids in all bars and plate specimens tested. The classification of materials as void or solid was done with VG STUDIO MAX 2.1 software. The solids and voids (trapped gas) are represented by two different peaks on the grey value distribution of the voxels in the volume scanned. Voids and solid were defined automatically based on statistical information about the voxels covered with a typical void (Darker) and solid (brighter) areas (Fig. 16). Void volume fraction in the inspected elements was measured by counting the relevant voxels. On metallographic cross section it was found that the voids with a diameter below $30 \mu \mathrm{m}$ could have significant share in the void volume fraction. Such small voids were not included in 
the void volume fraction (Table 5) estimated using the technique mentioned above. Among others it was most probably due to the geometric resolution of computed tomography being limited by the X-ray sources size (focal spot), detector pixel size and the magnification used (dependent FDD and FOD).

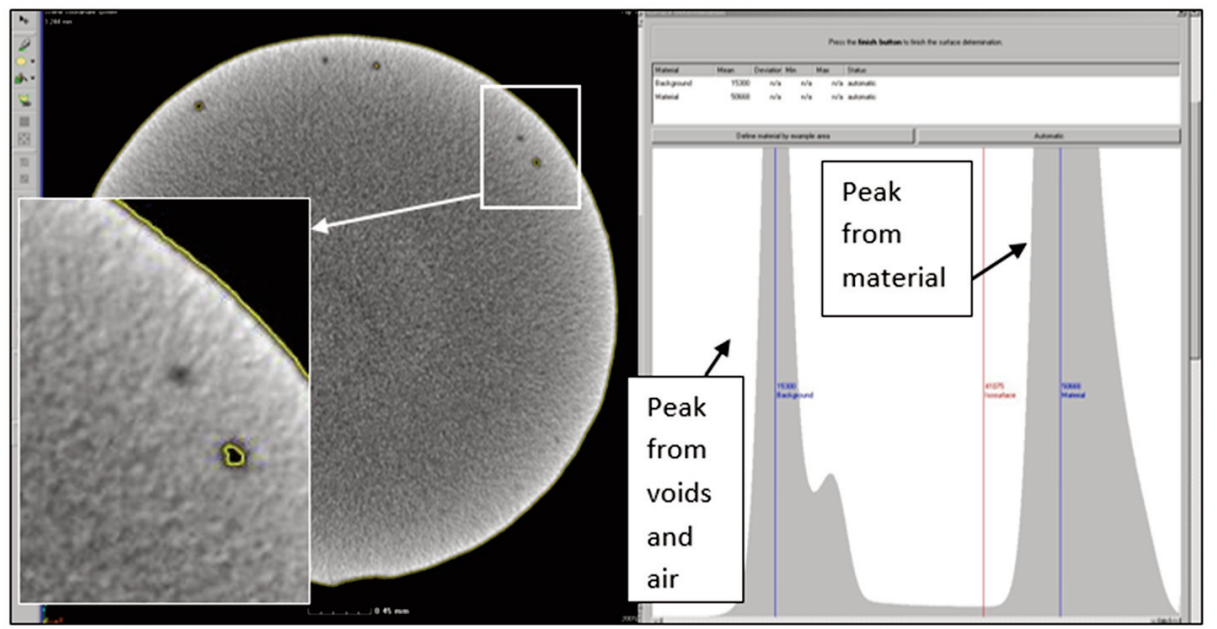

Fig. 16. Porosity evaluation technique of one of the raw bar using the surface analysis module available in the VG STUDIO MAX 21.
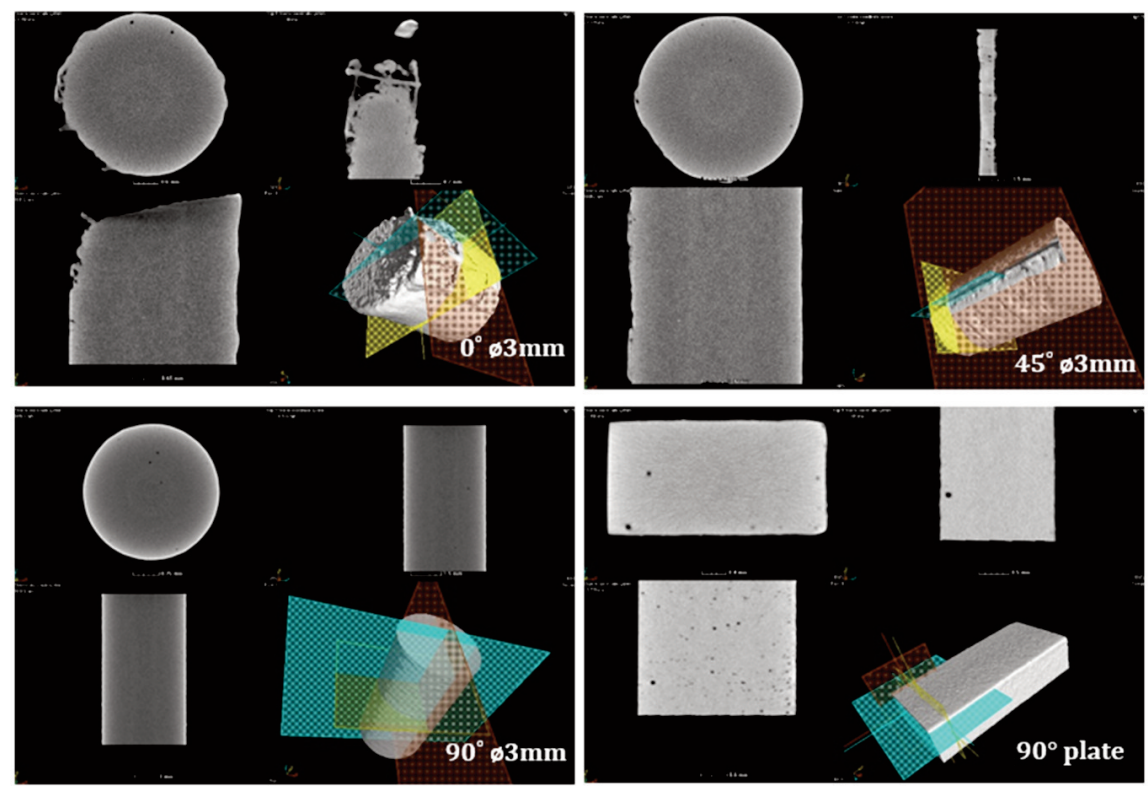

Fig. 17. CT of raw bars $ø 3 \mathrm{~mm}$ and plate type specimen after HT.

\section{CONCLUSSIONS}

- Tensile tests (YS 0.2\%, UTS, elongation) yielded values higher are than the minimum values required by the ASTM F3055 standards.

- Mechanical properties (YS $0.2 \%$ and UTS) were higher for D6 specimens $(\mathrm{d}=6.35 \mathrm{~mm})$ than for D5 specimens $(\mathrm{d}=4.06 \mathrm{~mm})$ by about $1-4 \%$. 
- In some specimens, in the surface area the micro cracks, non-melted zones and porosity were present. The most of these discontinuities were related to the specimen's support structures and could be removed by machining or surface finishing.

- Micro cracks and voids in the support surface area that are present in the specimens built in $0^{\circ}$ and $45^{\circ}$ directions, were one of the reasons of lower elongation and other mechanical properties compared with the values received in the specimens built in direction $90^{\circ}$.

- Carbides content in the specimens' surfaces was higher compared to the carbides content in the specimens' volume.

\section{REFERENCES}

[1] Trosch, T., Strößner, J., Völk1, R., Glatzel, U. (2016). Microstructure and mechanical properties of selective laser melted Inconel 718 compared to forging and casting. Mater Letters, 164, 428-431. DOI: 10.1016/j.matlet.2015.10.136.

[2] Strößner, J.,Terock, M., Glatzel, U. (2015). Mechanical and microstructural investigation of nickel-based superalloy IN718 manufactured by selective laser melting (SLM), Advanced Engineering Materials, 17(8), 1099-1105. DOI: 10.1002/adem.201500158.

[3] Li, X., Shi, J.J., Cao, G.H., Russell, A.M., Zhou, Z.J., Li, C.P., Chen, G.F. (2019). Improved plasticity of Inconel 718 superalloy fabricated by selective laser melting through a novel heat treatment process, Materials and Design, 18, 107915. DOI: 10.1016/j.matdes.2019.107915.

[4] Standard Specification for Additive Manufacturing Nickel Alloy (UNS N07718) with Powder Bed Fusion. ASTM F3055-14a.

[5] Standard Practice for Reporting Data for Test Specimens Prepared by Additive Manufacturing. ASTM F2971-13.

[6] Standard Test Methods for Tension Testing of Metallic Materials. ASTM E8/E8M$16 \mathrm{a}$.

[7] Liu, F., Lin, X., Leng, H., Cao, J. Liu, Q., Huang, Ch., Huang, W. (2013). Microstructural changes in a laser solid forming Inconel 718 superalloy thin wall in the deposition direction, Optics\&Laser Technology, 45, 330-335. DOI: 10.1016/j.optlastec.2012.06.028.

[8] Raza, T., Andresson, J., Svensson, L-E. (2018). Microstructure of Selective Laser Melted Alloy 718 in As-Manufactured and Post Heated Treated Condtition, Procedia Manufacturing, 25, 450-458. DOI: 10.1016/j.promfg.2018.06.100.

[9] Amato, K.N., Gaytan, S.M., Murr, L.E., Martinez, E., Shindo, P.W., Hernandez, J., Collins, S., Medina, F. (2012). Microstructures and mechanical behavior of Inconel 718 fabricated by selective laser metling, Acta Materialia, 60(5), 22292239. DOI: 10.1016/j.actamat.2011.12.032.

[10]Lu, Y., Wu, S., Gan,Y., Huang, T., Yang, Ch., Junjie, L., Lin, J. (2015). Study on the microstructure, mechanical property and residual stress of SLM Inconel-718 alloy manufactured by differing island scanning strategy, Optics\&Laser Technology, 75, 197-206. DOI: 10.1016/j.optlastec.2015.07.009. 